\title{
Zubrod Performance Status 1
}

National Cancer Institute

\section{Source}

National Cancer Institute. Zubrod Performance Status 1. NCI Thesaurus. Code C19999.

Restricted in physically strenuous activity but ambulatory and able to carry out work of a light or sedentary nature, e.g., light house work, office work (Eastern Cooperative Oncology Group) 